\title{
Diversidade genética para a padronização do tempo e percentual de hidratação preliminar ao teste de cocção de grãos de feijão
}

\author{
Genetic diversity in common beans to standardized pre-cooking soak time and hydration level for quality tests
}

Luiz Carlos BORDIN ${ }^{1}$, Cileide Maria Medeiros COELHO ${ }^{2 *}$, Clovis Arruda de SOUZA ${ }^{1}$, Marcio ZILIO ${ }^{1}$

\section{Resumo}

O tempo de hidratação prévio à cocção varia de 2 a 18 horas, o que dificulta estabelecer um padrão que proporcione o menor tempo de cocção. O objetivo do trabalho foi utilizar a diversidade genética, de genótipos crioulos, para avaliar o efeito da capacidade de hidratação sobre a cocção dos grãos de feijão, visando padronizar um percentual e/ou um tempo mínimo de hidratação prévio à cocção. Foram utilizados 18 genótipos crioulos e 4 comerciais, das safras 2006/2007 e 2007/2008. Realizaram-se os tratamentos de hidratação dos grãos (água ultrapura, a $25^{\circ} \mathrm{C}$ ) por $0,2,4,6$ e 8 horas, e até o ponto de estabilização, seguidos pela determinação do tempo de cocção nos respectivos tratamentos. Baseado nos resultados obtidos, os 22 genótipos avaliados apresentaram ampla diversidade genética para tempo de cocção. Assim, foi possível indicar 7 horas e $82,5 \%$ de hidratação como padrão de hidratação prévia aos testes de cocção, tanto para seleção precoce de linhagens como para inclusão desta metodologia na determinação do tempo de cocção nos ensaios de Valor de Cultivo e Uso (VCU), o qual é necessário para registro de nova cultivar no Ministério da Agricultura. O fator rápido tempo de cocção nos grãos foi associado ao processo de hidratação prévio inferior a máxima hidratação, o que proporcionou economia de tempo e maior representabilidade nos resultados obtidos.

Palavras-chave: Phaseolus vulgaris L.; capacidade de hidratação; tempo de cocção; qualidade tecnológica.

\begin{abstract}
before cooking, common beans require a soaking time varying from 2 to 18 hours depending on the genotype, which makes it difficult to standardize the soaking time in order to reach the shortest cooking time. The objective of this work was to evaluate the effect of bean hydration capacity to standardize the shortest cooking time. Eighteen bean landraces and four commercial lines from plants cultivated under the same conditions for two growing seasons (2006/2007 and 2007/2008) were used in this study. The beans were soaked completely or partially for 0 , $2,4,6$, or 8 hours in pure water at $25^{\circ} \mathrm{C}$, followed by cooking time determination. The results showed that 22 genotypes evaluated presented high genetic diversity leading to great variability of cooking time, and they also indicated that seven hours of soaking was necessary to obtain a minimum of $82.5 \%$ hydration as an optimized condition to reach the fastest cooking time. Considering these findings, cooking tests for an early selection of bean lineages can be standardized and can be used to standardize Usage Value Analysis (UVA), which is usually required for official registration of common bean cultivar.
\end{abstract}

Keywords: Phaseolus vulgaris L.; soaking; cooking time; technological trait.

\section{Introdução}

O feijão é um alimento de grande importância econômica e social, constituindo, juntamente com o arroz, a base da dieta do povo brasileiro (MOURA; PAIVA; RESENDE, 1994). Apesar de sua importância, e do fato de o Brasil ser o maior produtor de feijão (Phaseolus vulgaris L.), seu consumo vem diminuindo (ROMANO et al., 2005a), principalmente devido ao limitado tempo para o preparo das refeições (BELICUAS; RAMALHO; ABREU, 2001). Assim, para reversão desse quadro, é de suma importância que além de elevadas produtividades que são obtidas nas variedades comerciais de feijão, deve-se considerar a seleção de genótipos que apresentem tempo de cocção reduzido (CARBONELL; CARVALHO; PEREIRA, 2003).

Na seleção precoce das linhagens, bem como, nos ensaios de Valor de Cultivo e Uso (VCU), são realizados testes de hidratação prévios à cocção para a introdução ou descarte dos genótipos, porém, na literatura, observam-se divergências quanto aos tempos de hidratação, os quais variam de 2 a 18 horas, o que dificulta a comparação dos resultados obtidos. Apesar de existir uma metodologia a ser utilizada, descrita na Instrução Normativa no 25 de 23/05/2006 do Ministério da Agricultura, Pecuária e Abastecimento-MAPA (BRASIL, 2006) que considera o padrão o tempo de 16 horas de hidratação em água destilada (PROCTOR; WATTS, 1987), isto não é usado em todos os trabalhos, pois se constataram diferentes tempos de hidratação dos grãos, de 18 horas (GARCIA-VELA; STANLEY, 1989), 16 horas (CARBONELL; CARVALHO; PEREIRA, 2003; DALLA CORTE et al., 2003), de 12 horas (LEMOS et al., 2004; RAMOS JUNIOR; LEMOS; SILVA, 2005), de 8 horas (RODRIGUES et al., 2004), de 4 horas (COSTA; RAMALHO; ABREU, 2001) e de 2 horas (RODRIGUES et al., 2004). Portanto, em razão dessas divergências, há necessidade da padronização do tempo e/ou do percentual de hidratação dos grãos, previamente ao tempo de cocção.

Recebido para publicação em 23/7/2008

Aceito para publicação em 8/7/2009 (003701)

${ }^{1}$ Departamento de Agronomia, Centro de Ciências Agroveterinárias, Universidade do Estado de Santa Catarina - UDESC, CEP 88502-970, Lages - SC, Brasil

${ }^{2}$ Departamento de Fitotecnia, Centro de Ciências Agrárias, Universidade Federal de Santa Catarina - UFSC, CEP 88034-001, Florianópolis - SC, Brasil, E-mail: cileide@cca.ufsc.br

${ }^{*}$ A quem a correspondência deve ser enviada 
O fato dos grãos permanecerem tempo prolongado no processo de hidratação pode causar perdas significativas de proteínas solúveis e sólidos totais na água de hidratação não absorvida pelos grãos (ROMANO et al., 2005a). Apesar do tempo de cozimento diminuir com o aumento do tempo de permanência dos grãos em embebição, tempos de 16 horas de permanência dos grãos de feijão em hidratação antes da avaliação do tempo de cozimento podem ser desnecessários, já que nem sempre possibilitam cozimento mais rápido (CARNEIRO, J. D. S.; ARAUJO; CARNEIRO, J. E. S., 1999; CARBONELL; CARVALHO; PEREIRA, 2003; DALLA CORTE et al., 2003).

A grande dificuldade de avaliar o tempo de cocção está na identificação de um método que seja eficiente e rápido. $\mathrm{O}$ uso da capacidade de hidratação dos grãos, alternativamente pode ser um parâmetro para a seleção precoce de genótipos para o menor tempo de cocção, desde que o fator "menor tempo" para o grão atingir a sua máxima hidratação seja um indicativo do menor tempo de cocção. Esta relação direta é encontrada por alguns autores (IBARRA-PERÉZ; CASTILHO; CUELLAR, 1996; RODRIGUES et al., 2005), mas não é regra, pois, nem sempre a maior capacidade dos grãos hidratarem indica menor tempo de cocção (CARBONELL; CARVALHO; PEREIRA, 2003; DALLA CORTE et al., 2003). Assim, características que podem estar relacionadas com o cozimento, como a quantidade de água absorvida pelos grãos, podem ser utilizadas na identificação de genótipos para menor tempo de cozimento.

As dificuldades em obter genótipos com menor tempo de cocção são elevadas, considerando-se que no melhoramento existe grande pressão na seleção de cultivares mais uniformes (tamanho, formato, coloração do tegumento dos grãos) e produtivas, assim muitas espécies cultivadas podem ser mais vulneráveis devido ao estreitamento da base genética (genótipos elites como fonte base de programas de melhoramento), que pode levar à perda de alguns caracteres, como qualidade tecnológica e nutricional dos grãos. Tais caracteres têm mais chances de serem encontrados em genótipos crioulos, por possuírem uma base genética mais ampla e maior proporção de genes distintos devido à grande diversidade genética (LOARCE; GALLEGO; FERRER, 1996; COELHO et al., 2007b).

Sendo assim, evidencia-se o desenvolvimento de metodologias que possibilitem a identificação precoce de genótipos com menor tempo de cozimento, através do conhecimento prévio da capacidade de hidratação dos grãos de feijão. Portanto, este trabalho teve como objetivo utilizar a diversidade genética de genótipos crioulos para avaliar o efeito da capacidade de hidratação sobre a cocção dos grãos de feijão, com o intuito de padronizar um percentual e/ou um tempo mínimo de hidratação prévio à cocção.

\section{Material e métodos}

Os 22 genótipos de feijão (18 crioulos +4 comerciais) foram previamente selecionados, sendo os crioulos selecionados quanto às características agronômicas desejáveis como cor da semente, hábito de crescimento e produtividade e também ampla diversidade no tempo de cocção, provenientes do Banco Ativo de Feijão (BAF) do CAV/UDESC (BAF’s03, 04, 07, 11, 13,
26, 41, 42, 44, 46, 50, 55, 58, 75, 81, 84, 97, 102) e os 4 genótipos comerciais por serem recomendados para a região: BAF111 (Pérola), BAF112 (IPR-88-Uirapurú), BAF115 (BRS-Valente) e BAF121 (Iapar 81).

O experimento foi conduzido a campo sob delineamento experimental em blocos inteiramente casualizados, com três repetições, nas safras agrícolas de 2006/2007 e 2007/2008 (ano 1 e 2), em Lages, localizado no Planalto Sul de Santa Catarina. As coordenadas geográficas deste município são $27^{\circ} 52^{\prime} 30^{\prime \prime}$ de latitude sul e $50^{\circ} 18^{\prime} 20^{\prime \prime}$ de longitude oeste, com altitude média de $930 \mathrm{~m}$ e caracterizado pela presença de verões brandos com chuvas bem distribuídas (EMPRESA..., 2008). O principal objetivo do experimento foi obter grãos novos e produzidos nas mesmas condições, visto que o ambiente de cultivo e o armazenamento afetam o tempo de cozimento (CARBONELL; CARVALHO; PEREIRA, 2003; COELHO et al., 2007a).

Os genótipos foram multiplicados para obtenção de sementes novas utilizando recomendação de adubação para a cultura do feijoeiro segundo Manual de Adubação e Calagem para o Rio Grande do Sul e Santa Catarina (COMISSÃO..., 2004).

Os grãos recém-colhidos foram previamente padronizados para $12 \%$ de umidade e as amostras foram armazenadas em câmara fria $\left(5^{\circ} \mathrm{C}\right)$, visando evitar o envelhecimento acelerado (COELHO et al., 2007a), até serem analisadas quanto à capacidade de hidratação e tempo de cocção.

\subsection{Capacidade de hidratação}

A capacidade de hidratação foi determinada de duas maneiras, a primeira até atingir a estabilização (máxima eficiência técnica) e a segunda consistiu em submeter os grãos aos tratamentos de embebição: 0, 2, 4, 6 e 8 horas. Para ambos os testes realizou-se a pesagem de $16 \mathrm{~g}$ de grãos de feijão acondicionados em um erlenmayer ao qual foi feita a adição de $100 \mathrm{~mL}$ de água ultra pura (MilliQ), na proporção de 1:6,25 $(\mathrm{p} / \mathrm{v})$ respectivamente, à temperatura de $25^{\circ} \mathrm{C}$ (COELHO et al., 2007a), mantidos em banho-maria e, a cada intervalo de 1 hora, os grãos foram pesados. No primeiro caso, até os grãos apresentarem-se completamente hidratados, ou seja, quando estabilizou a massa, num intervalo de três medidas consecutivas. No segundo, as medidas de hidratação, apenas nos tempos previamente estabelecidos. Após os tempos pré-determinados (2, 4, 6 e 8 horas), os grãos foram retirados e parcialmente secos com papel toalha, para retirar o excesso de água junto ao tegumento. $\mathrm{O}$ valor de absorção de água nos grãos foi expresso em percentagem de água absorvida através da seguinte fórmula: [(massa do grão hidratado - massa do grão seco)/massa do grão seco] $\times 100$ (BERRIOS; SWANSON; CHEONG, 1999).

\subsection{Tempo de Cocção (TC)}

Os grãos que atingiram sua estabilização de hidratação e aqueles hidratados apenas por 2, 4, 6 e 8 horas de hidratação, foram submetidos à cocção. Como propõe a metodologia oficial, o tempo de cocção foi determinado através da utilização do equipamento "cozedor de Mattson" (PROCTOR; WATTS, 
1987). O cozimento foi sob água destilada fervente $\left(\sim 96^{\circ} \mathrm{C}\right)$ : à medida que ocorria o cozimento, as hastes caíam e atravessavam os grãos, anotando-se o tempo decorrido do início da fervura até a queda das hastes. O tempo de cozimento foi considerado quando 13 hastes (50\% mais uma) perfuraram os grãos.

\subsection{Análises estatísticas}

Os dados foram submetidos à análise de variância, utilizando-se teste $\mathrm{F}$ para verificar efeito de tratamento, ou seja, testar as hipóteses relativas aos efeitos principais e da interação, genótipo $\times$ ano. $\mathrm{O}$ desdobramento dos graus de liberdade e a comparação entre ano para cada genótipo foi realizado pelo teste de $T$ a $5 \%$ de probabilidade de erro. Em complementação, realizou-se análise de regressão para caracterizar o comportamento dos genótipos nos diferentes tempos e capacidade de hidratação e suas relações com os tempos de cocção.

\section{Resultados e discussão}

À medida que se aumentou o tempo de hidratação, de 2, 4, 6 para 8 horas, observou-se aumento no percentual de hidratação em todos os genótipos nos anos 1 e 2 (2006/2007 e 2007/2008), e constatou-se que o tempo de máxima capacidade de hidratação foi de 9,4 horas e $81,4 \%$ de hidratação (ano 1) e tempo de 7,2 horas e $85,6 \%$ no ano 2 (Figura 1). Este comportamento fornece indícios de que não é necessário tempo de 16 horas para obter a máxima hidratação, como proposto por Proctor e Watts (1987). Particularmente, no tempo de 8 horas, constatou-se que 82 e 100\% dos genótipos apresentaram alta capacidade de hidratação, com valores acima de 70\%, em ambos os anos de cultivo $(1,2)$. Contudo, um elevado percentual de hidratação isoladamente não serve de parâmetro, é necessário relacioná-lo com o tempo de cocção.
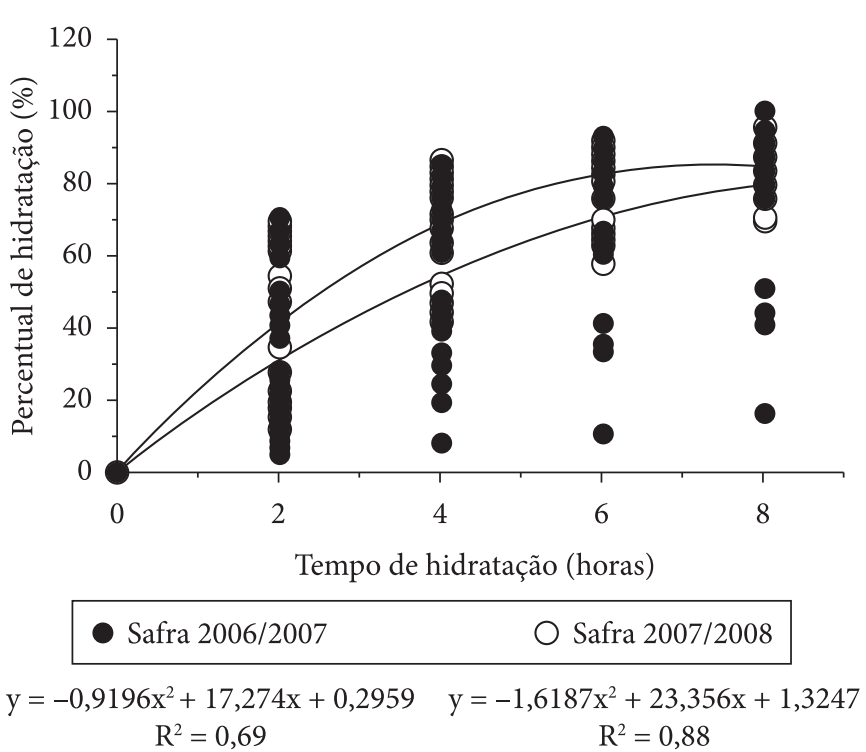

Figura 1. Comportamento de 22 genótipos de feijão quanto à capacidade de hidratação (percentual) em função do tempo de hidratação nas safras 2006/2007 e 2007/2008.
Ao se relacionar os diferentes tempos de hidratação $(0$ a 8 horas) com os respectivos tempos de cocção, observou-se o ponto de mínima no tempo de cocção ( 34,9 minutos) com 6,9 horas de hidratação no ano 1 , e de 21,7 minutos com 7,2 horas de hidratação no ano 2 (Figura 2). Estes resultados reforçam a hipótese proposta neste trabalho de que não são necessárias 16 horas de hidratação prévia para a determinação do tempo de cocção em grãos de feijão. Mas, para confirmação desta hipótese, determinou-se a relação do tempo de cocção também com o percentual de hidratação (Figura 3), e verificou-

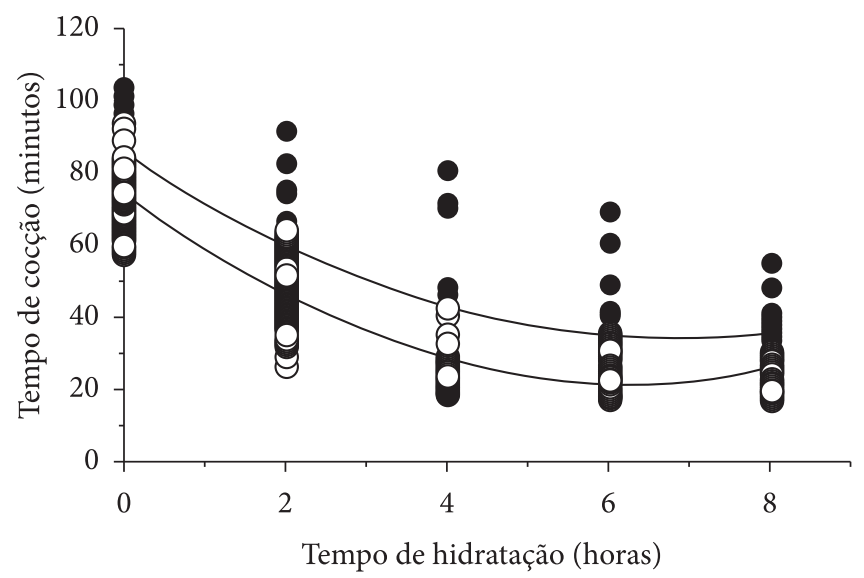

$$
\begin{array}{cc|}
\hline \text { Safra } 2006 / 2007 & \text { O Safra 2007/2008 } \\
\hline \mathrm{R}^{2}=0,71 & \mathrm{y}=1,2687 \mathrm{x}^{2}-16,099 \mathrm{x}+72,781 \\
\mathrm{R}^{2}=0,87
\end{array}
$$

Figura 2. Relação entre tempo de hidratação e respectivo tempo de cocção de 22 genótipos de feijão sob hidratação dos grãos de zero a oito horas de 22 genótipos de feijão, nas safras 2006/2007 e 2007/2008.

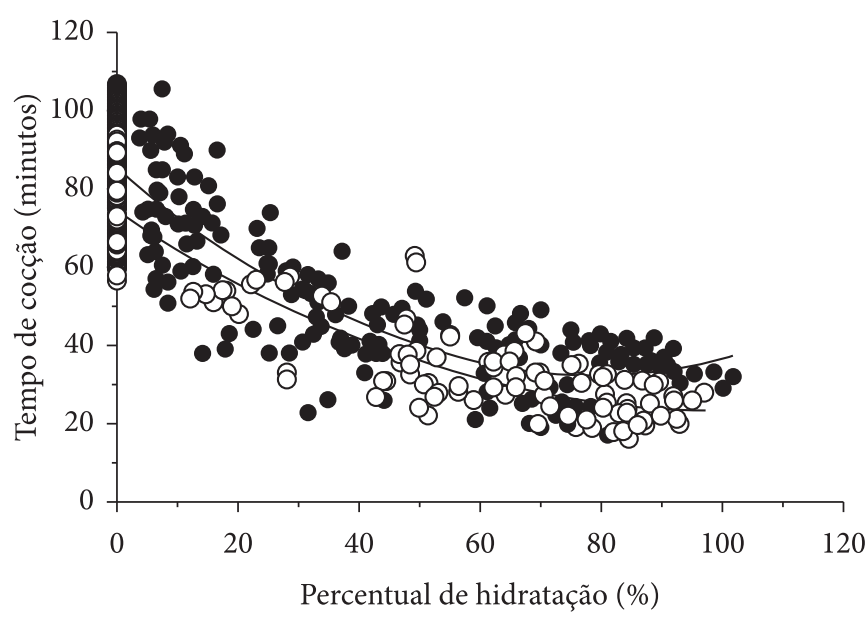

$$
\begin{array}{cc|}
\hline \text { Safra 2006/2007 } & \text { O Safra 2007/2008 } \\
\hline \mathrm{R}^{2}=0,81 & \mathrm{y}=0,005 \mathrm{x}^{2}-0,9969 \mathrm{x}+73,539 \\
\mathrm{R}^{2}=0,89
\end{array}
$$

Figura 3. Relação entre percentual de hidratação e tempo de cocção de 22 genótipos de feijão sob hidratação dos grãos de zero a oito horas (símbolos abertos, safra 2006/2007 com r = -0,85; símbolo fechado safra 2007/2008 com $r=-0,92)$. 
se para o ano 1 o tempo mínimo de cocção de 30,5 minutos com um percentual de $82,6 \%$ de hidratação, e no ano 2 o tempo mínimo de cocção foi de 23,9 minutos com 99\% de hidratação. Estes resultados indicam que o grão deve ter atingido percentual mínimo de hidratação para a determinação do tempo de cocção, mas também indicam que as condições ambientais de cultivo de um ano para o outro afetam ambos o percentual de hidratação e o tempo de cocção. Entretanto, mesmo assim, um tempo inferior a 8 horas de hidratação foi suficiente para detectar tais diferenças, tanto entre genótipos quanto entre os anos de cultivo.

A relação encontrada entre menor tempo de cocção com maior percentual de hidratação concorda com os resultados observados por Jacinto et al. (1999), que relatam correlação negativa e significativa entre absorção de água e o tempo de cozimento, mas contraria aquele obtido por Dalla Corte et al. (2003), que encontraram correlação positiva e alta $(\mathrm{r}=+0,51)$, por Carbonell, Carvalho e Pereira (2003), que obtiveram valores de baixa-média magnitude $(\mathrm{r}=-0,19 \mathrm{a}+0,22)$ entre as variáveis absorção de água e tempo de cozimento e por Ramos Junior, Lemos e Silva (2005), que sugerem ausência desta relação. Provavelmente, a obtenção destas respostas diferenciadas seja em decorrência de falta de padronização metodológica no teste de absorção de água pelos grãos previamente à cocção e/ou de diferenças genotípicas e ambientais.

Devido à interação genótipo $\mathrm{x}$ ano, fez-se a comparação entre anos de cultivo ( 1 e 2) para cada genótipo no tempo específico de 8 horas de hidratação, e verificou-se que o percentual de hidratação diferiu significativamente para 55\% dos genótipos e que, na média, o percentual de hidratação foi maior no ano 2 $(8,4 \%)$ (Tabela 1). Em relação ao tempo de cocção, observouse efeito altamente significativo entre os anos de cultivo para a maioria dos genótipos $(95,5 \%)$ e, na média, o tempo de cocção foi menor em 9,9 minutos no ano 2 (Tabela 1).

A ampla diversidade entre os genótipos escolhidos para este experimento foi verificada pela variação observada nos valores de percentual de hidratação e tempo de cocção. O percentual de hidratação variou de 16,4 a 100,4\%, (média de 77,6\%) no ano 1 , e 69,8 a $96,3 \%$ no ano 2 (média de $86 \%$ ). O tempo de cocção foi entre 19,5 e 47,5 minutos (média 33,3 minutos) no ano 1 e de 17,5 a 28 minutos (média 23,4 minutos) no ano 2 (Tabela 1).

Em vários trabalhos, tem-se demonstrado a existência da interação genótipos e ambientes para o caráter tempo de cocção e observaram-se diferenças no comportamento das linhagens e das cultivares em diferentes locais, anos agrícolas e nas épocas de semeadura (RAMALHO; ABREU; SANTOS, 1993; DUARTE; ZIMMERMANN, 1994; PIANA et al., 1999; CARBONELL; POMPEU, 2000). Esta interação pode ser explicada pela possibilidade de interferência das condições ambientais na qualidade fisiológica e na alteração da integridade do tegumento dos grãos, tendo como consequência mudanças quanto à capacidade de absorção de água e no tempo de cozimento (SCHOLZ; FONSECA JUNIOR, 1999a, b).

Tabela 1. Percentagens de hidratação e respectivos tempos de cocção de 22 genótipos de feijão quando submetidos a embebição prévia de 8 horas.

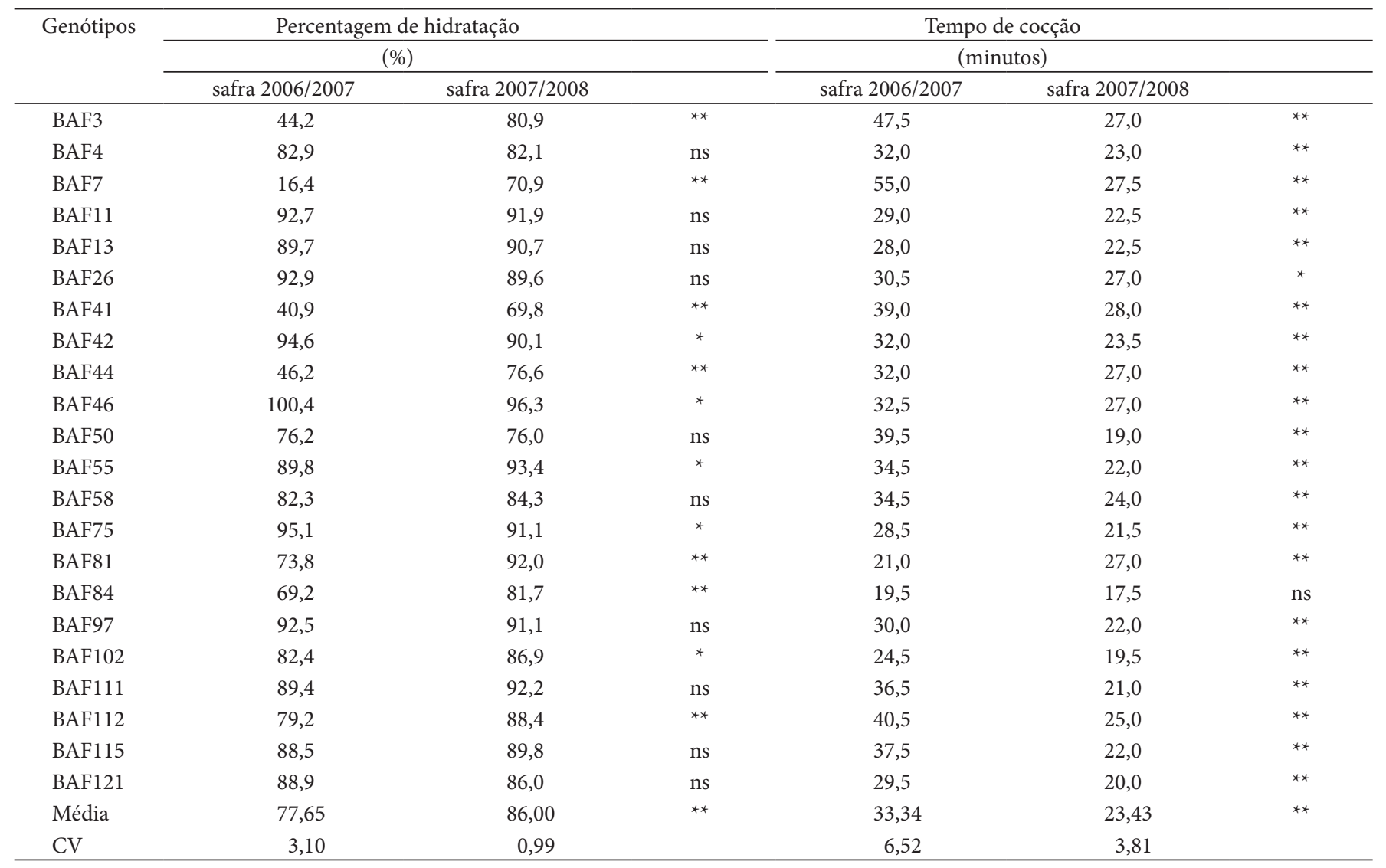


Apesar do efeito de ano de cultivo, observaram-se genótipos promissores para baixo tempo de cocção, os quais foram os BAFs 84 e 102 em relação ao BAF 121 (Iapar 81), com tempos médios nos dois anos de cultivo de 18,5 e 22 minutos. Estes tempos são considerados de susceptibilidade média e resistência normal ao cozimento, respectivamente (RAMOS JUNIOR; LEMOS; SILVA, 2005).

Para confirmar que não seria necessário um tempo superior a 8 horas de hidratação, conduziram-se também as análises na condição de estabilização da hidratação (máxima capacidade de hidratação). Para isto, observaram-se as diferenças entre os genótipos e sua interação com ano de cultivo, e constatou-se que o tempo de hidratação foi significativamente diferente em $63,6 \%$ dos genótipos entre os anos 1 e 2 , com um tempo médio de 8,4 e 10,8 minutos, respectivamente (Tabela 2). Ressalta-se que apenas dois genótipos (BAF 3 e 7) requereram tempos de 15,5-16 horas para alcançarem a máxima hidratação.

Em comparação com a literatura, os trabalhos mostram tempos semelhantes para a máxima capacidade de hidratação, entre 8 horas 10 minutos e 12 horas 1 minuto para 15 cultivares do grupo comercial Carioca, e tempos de cocção entre 33 a 45 minutos (RAMOS JUNIOR; LEMOS; SILVA, 2005). Em outro trabalho, também com feijão do grupo comercial Carioca, dos 29 genótipos, 28 (96,6\%) apresentaram tempo de máxima hidratação, entre 8 horas 8 minutos e 10 horas 58 minutos em dois anos consecutivos, 2001 e 2002 (LEMOS et al., 2004). Para as cultivares de feijão Guapo Brilhante e Pérola, 52\% de hidratação, referente a 5 horas de embebição foi suficiente para obter o menor tempo de cozimento (ROMANO et al., 2005b).
Quanto ao percentual de hidratação, na condição de máxima hidratação, constataram-se diferenças significativas em $45,5 \%$ dos genótipos, com média de 88,5 e $91,8 \%$ no ano 1 e 2 , respectivamente. Já no tempo de cocção, 63,6\% dos genótipos diferiram, com uma média de tempo de 30,7 e 24,6 minutos nos respectivos anos (Tabela 2). É importante salientar que, mesmo deixando os grãos por mais tempo no processo de hidratação, o tempo de cocção médio foi semelhante ao obtido quando os grãos permaneceram apenas por 8 horas prévias na hidratação (Tabela 1, 2 e Figura 3), o que evidencia não ser necessário que o grão permaneça 16 horas no processo de hidratação, como o recomendado pela Instrução Normativa no 25 de 23/05/2006 do Ministério da Agricultura, Pecuária e Abastecimento-MAPA (BRASIL, 2006), o qual cita o trabalho de Proctor e Watts (1987) como referência.

A existência da variabilidade genética para o teste de absorção de água pelos grãos de feijão tem sido relatada por diversos autores (COSTA; RAMALHO; ABREU, 2001; RAMOS JUNIOR; LEMOS, 2002; RIBEIRO et al., 2003; COELHO et al., 2007b). Este fato sugere que a seleção para essa característica (maior hidratação) pode ser útil na identificação precoce de linhagens com maior facilidade para o cozimento, desde que a correlação existente entre essas características seja de alta magnitude, $92 \%$ e 37 minutos de cocção (RAMOS JUNIOR; LEMOS, 2002) e correlação negativa, $r=-0,79$ para TPS Nobre e $r=-0,91$ para Pérola (RODRIGUES et al., 2005).

Tabela 2. Tempo necessário para alcançar a Capacidade Máxima de Hidratação (TCMH) e respectivas percentagens de hidratação e tempos de cocção de 22 genótipos de feijão.

\begin{tabular}{|c|c|c|c|c|c|c|c|c|c|}
\hline \multirow[t]{3}{*}{ Genótipos } & \multicolumn{3}{|c|}{ TCMH } & \multirow{2}{*}{\multicolumn{2}{|c|}{$\frac{\text { Percentagem de hidratação }}{(\%)}$}} & \multicolumn{4}{|c|}{ Tempo de cocção } \\
\hline & \multicolumn{2}{|c|}{ (horas) } & & & & & \multicolumn{2}{|c|}{ (minutos) } & \\
\hline & safra $2006 / 2007$ & safra $2007 / 2008$ & & safra 2006/2007 & safra $2007 / 2008$ & & safra 2006/2007 & safra $2007 / 2008$ & \\
\hline BAF3 & 11,0 & 16,0 & $* *$ & 76,0 & 86,8 & $* *$ & 40,9 & 25,0 & $* *$ \\
\hline BAF4 & 10,0 & 11,0 & ns & 86,6 & 90,6 & ns & 28,7 & 23,0 & $* *$ \\
\hline BAF7 & 11,5 & 15,5 & $* *$ & 49,2 & 84,2 & ** & 38,1 & 34,0 & * \\
\hline BAF11 & 8,0 & 10,3 & $* *$ & 92,7 & 94,7 & ns & 27,0 & 23,5 & ns \\
\hline BAF13 & 8,0 & 9,5 & ns & 97,1 & 93,4 & ns & 29,3 & 23,0 & $* *$ \\
\hline BAF26 & 7,0 & 12,0 & $* *$ & 94,2 & 99,7 & * & 31,0 & 26,0 & * \\
\hline BAF41 & 12,5 & 12,0 & $\mathrm{~ns}$ & 83,5 & 90,4 & * & 34,5 & 27,0 & $* *$ \\
\hline BAF42 & 5,5 & 9,5 & $* *$ & 95,4 & 88,8 & * & 26,2 & 23,5 & ns \\
\hline BAF44 & 9,5 & 12,5 & $* *$ & 83,1 & 80,4 & ns & 27,0 & 25,0 & ns \\
\hline BAF46 & 7,0 & 8,5 & ns & 100,9 & 96,3 & ns & 35,7 & 27,0 & $* *$ \\
\hline BAF50 & 10,0 & 11,0 & ns & 88,1 & 78,6 & ** & 47,6 & 24,5 & $* *$ \\
\hline BAF55 & 5,0 & 11,5 & $* *$ & 88,9 & 93,7 & ns & 30,4 & 25,5 & * \\
\hline BAF58 & 8,0 & 10,5 & $* *$ & 81,8 & 91,3 & $* *$ & 29,9 & 22,0 & $* *$ \\
\hline BAF75 & 7,5 & 10,5 & $* *$ & 96,1 & 92,8 & ns & 25,7 & 25,5 & ns \\
\hline BAF81 & 8,0 & 11,0 & $* *$ & 91,7 & 91,2 & ns & 26,3 & 25,5 & ns \\
\hline BAF84 & 8,0 & 10,5 & $* *$ & 98,0 & 99,5 & ns & 23,7 & 17,5 & $* *$ \\
\hline BAF97 & 9,5 & 6,5 & $* *$ & 89,5 & 101,4 & $* *$ & 25,5 & 22,5 & ns \\
\hline BAF102 & 8,0 & 8,5 & ns & 85,8 & 90,0 & ns & 25,1 & 22,5 & ns \\
\hline BAF111 & 7,5 & 11,5 & $* *$ & 95,9 & 95,8 & ns & 35,0 & 23,0 & $* *$ \\
\hline BAF112 & 8,0 & 9,5 & ns & 87,7 & 90,6 & ns & 29,5 & 25,0 & * \\
\hline BAF115 & 8,0 & 9,5 & $\mathrm{~ns}$ & 94,7 & 87,1 & $* *$ & 27,0 & 25,5 & ns \\
\hline BAF121 & 7,0 & 10,5 & $* *$ & 91,3 & 101,5 & $* *$ & 31,2 & 26,0 & * \\
\hline Média & 8,39 & 10,81 & $* *$ & 88,52 & 91,76 & $* *$ & 30,69 & 24,64 & $* *$ \\
\hline $\mathrm{CV}$ & 5,78 & 9,16 & & 4,29 & 0,72 & & 8,77 & 3,78 & \\
\hline
\end{tabular}


Deste modo, os resultados obtidos neste trabalho confirmaram a hipótese de que o tempo de imersão dos grãos deve ser inferior a 8 horas, principalmente através da determinação do tempo e do percentual mínimo de hidratação alcançado para o menor tempo de cocção, o qual juntamente com a comparação entre os tempos de máxima capacidade hidratação permitiram indicar o de 7 horas de hidratação como tempo padrão. Estes resultados concordam com Rodrigues et al. (2004), que sugerem o tempo de 8 horas de embebição dos grãos de feijão como suficientes para a avaliação do teste de absorção de água e para a quantificação do tempo de cozimento, com uso de 19 genótipos comerciais.

Em complemento, considerando que os 22 genótipos ( 18 crioulos +4 comerciais) avaliados neste trabalho apresentam ampla diversidade genética para tempo de cocção, foi possível indicar 7 horas e $82,5 \%$ de hidratação como tempo padrão de hidratação prévia aos testes de cocção, tanto para seleção precoce de linhagens como para inclusão desta metodologia na determinação do tempo de cocção nos ensaios de Valor de Cultivo e Uso (VCU), o qual é necessário para registro de nova cultivar no Ministério da Agricultura. Assim, evidenciou-se que o fator rápido tempo de cocção nos grãos foi associado ao processo de hidratação prévio inferior à máxima hidratação, o que proporcionou economia de tempo e maior representabilidade nos resultados obtidos.

\section{Conclusões}

Conclui-se que o tempo de 7 horas de embebição dos grãos de feijão foi eficiente na caracterização dos genótipos para baixo tempo de cocção, atrelado ao percentual mínimo de $82,5 \%$ de hidratação. Ambos devem ser considerados como padrão tanto na seleção precoce de genótipos, como nos ensaios de valor de cultivo e uso de feijão.

Tanto a hidratação (percentagem e tempo) como a cocção são fatores influenciados pelo ano de cultivo.

\section{Agradecimentos}

Os autores agradecem à CAPES (Coordenação de Aperfeiçoamento de Pessoal de Nível Superior) o apoio financeiro via PRODOC (Programa de Apoio a Projetos Institucionais), concedido ao segundo autor (C.M.M Coelho).

\section{Referências bibliográficas}

BELICUAS, P. R.; RAMAlHO, M. A. P.; ABREU, A. F. B. Controle genético da capacidade de cozimento dos grãos de feijão. In: CONGRESSO BRASILEIRO DE MELHORAMENTO DE PLANTAS, 1., 2001, Goiânia, GO. Anais... Goiânia, GO: SBMP, 2001. 1 CD-ROM.

BERRIOS, J. D. J.; SWANSON, B. G.; CHEONG, W. A. Physicochemical characterization of stored black beans. Food Research International, v. 32, n. 10, p. 669-676, 1999.

BRASIL. Ministério da Agricultura, Pecuária e Abastecimento - MAPA. Anexo I - Requisitos mínimos para determinação do valor de cultivo e uso de feijão (Phaseolus vulgaris) para a inscrição no registro nacional de cultivares - RNC-2006. Brasília, DF, 2006.
Disponível em: <http://agricultura.gov.br>. Acesso em: 8 fev. 2008.

CARBONELL, S. A. M.; CARVALHO, C. R. L.; PEREIRA, V. R. Qualidade tecnológica de grãos de genótipos de feijoeiro cultivados em diferentes ambientes. Bragantia, v. 62, n. 3, p. 369-379, 2003.

CARBONELL, S. A. M.; POMPEU, A. S. Estabilidade fenotípica de linhagens de feijoeiro em rês épocas de plantio no Estado de São Paulo. Pesquisa Agropecuária Brasileira, Brasília, v. 35, n. 2, p. 321-329, 2000.

CARNEIRO, J. D. S.; ARAUJO, G. A. A.; CARNEIRO, J. E. S. Potencial tecnológico dos grãos de linhagens de feijão (Phaseulus vulgaris L.). In: REUNIÃO NACIONAL DE PESQUISA DO FEIJÃO, 6., 1999, Goiânia, GO. Anais... Goiânia, GO: Embrapa, 1999. p. 408-411.

COELHO, C. M. M. et al. Effect of phytate and storage conditions on the development of the hard to cook phenomenon in common beans. Journal of the Science of Food and Agriculture, v. 87, n. 7, p. 1237-1243, 2007a.

COELHO, C. M. M. et al. Diversidade genética em acessos de feijão (Phaseolus vulgaris L.). Ciência Rural, v. 37, n. 5, p. 1241-1247, 2007b.

COSTA, G. R.; RAMALHO, M. A. P.; ABREU, A. F. B. Variabilidade para a absorção de água nos grãos de feijão do germoplasma da UFLA. Ciência e Agrotecnologia, v. 25, n. 4, p. 1017-1021, 2001.

DALLA CORTE, A. et al. Environment effect on grain quality in early common bean cultivars and lines. Crop Breeding and Applied Biotechnology, v. 3, n. 3, p. 193-202, 2003.

DUARTE, J. B.; ZIMMERMANN, M. J. O. Adaptabilidade e estabilidade de rendimento de genótipo de feijoeiro comum. Pesquisa Agropecuária Brasileira, v. 29, n. 1, p. 25-32, 1994.

EMPRESA DE PESQUISA AGROPECUÁRIA E EXTENSÃO RURAL DE SANTA CATARINA - EPAGRI. Atlas climatológico do Estado de Santa Catarina. 2008. Disponível em: <http:://www.ciram. epagri.rct-sc.br>. Acesso em: 20 mar. 2008.

GARCIA-VELA, L. A.; STANLEY, D. W. Water-holding capacity in hard-to-cook beans (Phaseolus vulgaris): effect of $\mathrm{pH}$ and ionic strength. Jounal of Food Science, Chicago, v. 54, n. 4, p. 1080-1081, 1989.

IBARRA-PERÉZ, F. J.; CASTILHO, R.; CUELLAR, E. J. Treshing effect on cooking time in comercial beans cultivars from semiarid highlands of Mexico. Annual Report of the Bean Improvement Cooperative, v. 39, n. 1, p. 264-265, 1996.

JACINTO, C. H. et al. Seed physical traits and inheritance of cooking time in recombinant bean inbred lines. Annual Report of the Bean Improvement Cooperative, v. 42, n. 1, p. 125-126, 1999.

LEMOS, L. B. et al. Características agronômicas e tecnológicas de genótipos de feijão do grupo comercial carioca. Pesquisa Agropecuária Brasileira, v. 39, n. 4, p. 319-326, 2004.

LOARCE, Y.; GALLEGO, R; FERRER, E. A comparative analysis of the genetic relationship between rye cultivars using RFLP and RAPD markers. Euphytica, v. 88, n. 1, p. 107-115, 1996.

MOURA, P. A. M.; PAIVA, B. M.; RESENDE, L. M. A. Aspectos econômicos da cultura do feijão. Revista Informe Agropecuário, v. 17, n. 178, p. 67-72, 1994.

PIANA, C. F. B. et al. Adaptabilidade e estabilidade do rendimento de grãos de genótipos de feijão. Pesquisa Agropecuária Brasileira, v. 34, n. 4, p. 553-564, 1999.

PROCTOR, J. R.; WATTS, B. M. Development of a modified mattson bean cooker procedure based on sensory panel cookability evaluation. Canadian Institute of Food Science and Technology Journal, v. 20, n. 1, p. 9-14, 1987. 
RAMALHO, M. A. P.; ABREU, A. F. B.; SANTOS, J. B. Desempenho de progênies precoces de feijoeiro (Phaseolus vulgaris L.) em diferentes locais e épocas de plantio. Revista Ceres, v. 40, n. 229, p. 272-280, 1993.

RAMOS JUNIOR, E. U.; LEMOS, L. B.; SILVA, T. R. B. Componentes da produção, produtividade de grãos e características tecnológicas de cultivares de feijão. Bragantia, v. 64, n. 1, p. 75-82, 2005.

RAMOS JUNIOR, E. U.; LEMOS, L. B. Comportamento de cultivares de feijão quanto à produtividade e qualidade dos grãos. In: CONGRESSO NACIONAL DE PESQUISA DE FEIJÃO, 7., 2002, Viçosa, MG. Anais... Viçosa, 2002. p. 263-266.

RIBEIRO, N. D. et al. Variabilidade genética para absorção de água em grãos de feijão. Pesquisa Agropecuária Gaúcha, v. 9, n. 1-2, p. 77-83, 2003.

RODRIGUES, J. A. et al. Correlação entre absorção de água e tempo de cozimento em cultivares de feijão. Ciência Rural, v. 35, n. 1, p. 209-214, 2005.

RODRIGUES, J. A. et al. Standardization of imbibition time of common bean grains to evaluate cooking quality. Crop Breeding and Applied Biotechnology, v. 4, n. 4, p. 465-471, 2004.

ROMANO, C. et al. Avaliação de sólidos totais e proteína solúvel na água de hidratação de feijões (Phaseolus vulgaris L.). In: REUNIÃO
NACIONAL DE PESQUISA DO FEIJÃO, 6., 1999, Goiânia, GO. Anais... Goiânia: Embrapa, 2005a. p. 684-686.

ROMANO, C. et al. Relação entre curva de hidratação e tempo de cocção em feijões. In: REUNIÃO NACIONAL DE PESQUISA DO FEIJÃO, 6., 1999, Goiânia, GO. Anais... Goiânia: Embrapa, 2005b. p. 713-715.

SCHOLZ, M. B. S.; FONSECA JÚNIOR, N. S. Efeito de ambientes, dos genótipos e da interação genótipo $\mathrm{X}$ ambiente na qualidade tecnológica de feijão do grupo de cores no estado do Paraná. In: REUNIÃO NACIONAL DE PESQUISA DO FEIJÃO, 6., 1999, Goiânia, GO. Anais... Goiânia: Embrapa, 1999a. p. 339-342.

SCHOLZ, M. B. S.; FONSECA JÚNIOR, N. S. Influência ambiental, genotípicas e sua interação na qualidade tecnológica de feijão do grupo preto no Paraná. In: REUNIÃO NACIONAL DE PESQUISA DO FEIJÃO, 6., 1999, Goiânia, GO. Anais... Goiânia: Embrapa, 1999b. p. 389-392.

SOCIEDADE BRASILEIRA DE CIÊNCIA DO SOLO - SBCS. Comissão de Química e Fertilidade do Solo - CQFS-RS/SC. Manual de adubação e de calagem para os estados do Rio Grande do Sul e Santa Catarina. 10. ed. Porto Alegre: SBCS - Núcleo Regional Sul/UFRGS, 2004. 400 p. 